\title{
The Self-Referential Structure of an Everyday-Living Situation: A Phenomenological Ontology for Interpretive Systemology
}

\author{
Ramsés Fuenmayor ${ }^{1}$
}

This is the second article in a trilogy. In the preceding paper, an ontoepistemology for reductionism was presented. It thus constituted a contrasting counter-ontoepistemology for the systems approach. The present article is devoted to outlining an ontoepistemology for the systems approach which, in contrast with the former counter-ontoepistemology, can explain wholeness. Such an outline is organized around the description of the essentially dynamic structure of an everyday-living situation, so that the holistic character of what-ever-is-the-case may be put forward. The discussion concerning the structure of an everyday-living situation is performed under a phenomenological approach. Thus, the paper begins by presenting a very brief introduction to phenomenology.

KEY WORDS: Interpretive systemology; systems philosophy; soft systems thinking; critical systems thinking; phenomenology.

\section{INTRODUCTION}

The design of an ontoepistemology for the systems approach has been strongly influenced by Phenomenology, an ontoepistemology whose development began at the end of the last century and continued into this century.

In fact, the work of philosophers such as Martin Heidegger and MerleauPonty has been of great help in developing the ontoepistemological scheme presented in this work. Following this order of ideas, it seems convenient to take a "first look" at Phenomenology before outlining the aforementioned scheme. This qualification of a "first look" is due to the fact that Phenomenology can make sense only through the postulation of an ontology. One such Postulation, beginning with the ontological problem posed by a systems approach, is summarized after the Introduction.

\subsection{Introducing Phenomenology}

According to Heidegger, "the term 'phenomenology' expresses a maxim which can be formulated as 'to the things themselves'" (Heidegger, 1962, p. 50). "To the things themselves" is not to be confused with the reductionist search for things-

\footnotetext{
${ }^{1}$ Department of Interpretive Systemology, Universidad de Los Andes, Mérida, Venezuela.
} 
in-themselves. On the contrary, it means the search for the "whatness" of things as manifested on the stage of everyday life (Lebenswelt). It means the search for the manifold of meanings dynamically impressed on our "compromise" with the world. It means, as we shall see later, to study things "distinguishing" them from what they are not. In the "phenomenalist" intention of studying things in their manifestation, timidly admitted in Modern thought, "to the things themselves" is the tenet that announces Phenomenology as persevering with new strengths and a new approach.

The "phenomenalist" intention may be compared to the realist in Renaissance painting, especially comparable to the introduction of that fundamental element of realism in painting: perspective. Medieval paintings were mainly religious. They were composed of symbolic figures presenting a religious message; hence, their symbolic nature. Depending on their religious importance, figures placed in the background sometimes looked bigger than those placed in the foreground (Astorga, 1967). On the contrary, the introduction of perspective brought about the depiction of a scene just as it was manifested to the observer from a single standpoint. Lack of perspective is a sort of analytical description of each object within the scene without considering, from the standpoint of the observer, the "spatially" relative role of the whole scene. It can be said that perspective includes the viewpoint of the observer within the painting. Indeed, this viewpoint organizes the perspective of the scene.

Just as in perspective, the phenomenalist intention includes the viewpoint of the observer within the scene of the study. It attempts to describe the manifestation of things within the context of "being-in-the-world."

The etymological meaning of the word "phenomenology" sheds further light on its intention. The word "phenomenology" has two components: 'phenomenon' and 'logos.' Both of these go back to terms from Greek: фawoó $\mu \varepsilon v o v$ and $\lambda$ ó (Heidegger, 1962, p. 50). Heidegger explains phenomenology by examining the meaning of these two terms.

The Greek expression фawvó derived from the verb $\phi \alpha i v \varepsilon \sigma \theta \alpha$, which signifies "to show itself." Thus

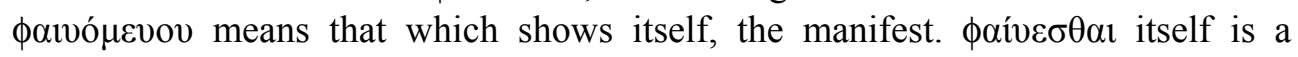
middle-voiced form which comes from $\phi \alpha w \omega$ - to bring to the light of day, to put

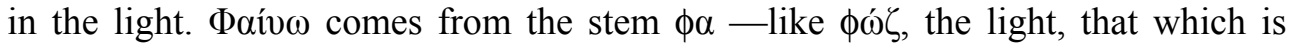
bright - in other words, that wherein something can become manifest, visible in itself. Thus we must keep in mind that the expression "phenomenon" signifies that which shows itself in itself, the manifest. (Heidegger, 1962, p. 51)

"Logos," on the other hand, is discursive (from "discourse") thought (whether stated or not) through which "things are discovered." It "is a letting-something-beseen" (Heidegger, 1962, p. 56) through discourse. Heidegger shows us how the original sense of the term contains and explains other meanings such as "reason," "treatise," and "synthesis" (Heidegger, 1962, pp. 55-58).

"Logos" pervades any way of access to phenomena. It can simply be there, 
without conscious direction, acting as a network interwoven into everyday life (Lebenswelt). Or, on the other hand, it can become the conscious and systematic tool for the search into phenomena. "Logos" can be directed so as to produce a discourse capable of throwing light on the being of objects. That is, a direction can be assigned to discourse that may bring it consistently closer to the phenomenon. [The criterion for getting closer, i.e., the concept of truth, is dealt with by Fuenmayor (1991b).]

By putting together the meaning of the two component terms, "phenomenon" and "logos," a preliminary comprehension of phenomenology can be obtained. Phenomenology, then, is the search for a phenomenon — that which shows itself in itself_through "logos."

Up to this point not enough has been said to characterize phenomenology since, as already stated, in this research method implicitly lies an ontology. Such ontology has to become manifest in order to delineate more precisely what phenomenology is. In the words of Thevenaz,

To the degree that phenomenology developed, it became increasingly clear that it had been from the beginning an ontology which, because of its very novelty, needed time to recognize itself as such. By this continual movement of goingbeyond and of progressive explication, phenomenology very naturally discovered and uncovered the ontology which sustained it and towards which it was tending. This was already apparent in Husserl; it became fully explicit in Heidegger. (Thevenaz, 1963, p.54)

However, a fundamental difference between Phenomenology and other scientific or philosophical attempts has already been mentioned: Things are not simply in themselves, nor do they exist "out there" independently from us. Their being is always constituted by a "showing themselves to us," and by our way of access to them.

Phenomenology emerges, within the last hundred years, accompanied by other trends of thought which share with it several ideas, particularly having in common the intention of understanding a reality where the observer cannot be torn away from the object of study. These trends share the intention of studying our "compromise" with reality (not reality as something independent from us) within the transcendental unity in which knowledge takes place. Interpretive Sciences, Hermeneutics, Social Phenomenology, and the Sociology of Knowledge as developed by W. Dilthey, M. Weber, A. Schutz, G. H. Mead, Max Scheler, T. Luckmann, P. Berger, etc., are close relatives of Philosophical Phenomenology.

After this brief introduction to phenomenology, the thread of the inquiry about a systems ontoepistemology must be resumed. Before starting, a final comment on discoursive style is due.

\subsection{A Comment on Discoursive Style}

The present Indo-European languages are, in varying degrees, constructed on 
the grounds of an Eleatic ontology (Fuenmayor, 1991a), which, in turn, is reinforced by our thinking through those languages. In order to break with such an ontology, it is necessary to sabotage the English language a little; so, the reader is asked not to be normatively horrified with some clumsy expressions, but just to be carried by them.

\section{THE NOTION OF SITUATION: A NOETIC PURVIEW}

What-ever-is-the-case (what is happening, what is going on) is possible only within a present ("now and here"), particular, concrete, circumstantial situation.

What is a situation? Is there a general "structure" or "process" taking place in any situation? The description of this concept of situation is initiated with a quotation from Mallin regarding Merleau-Ponty's ontology:

The sense of situation in which we are interested is roughly synonymous with "involvement in circumstances" or "active concern with sets of natural, cultural or human problems." We are using this sense when we say, for example, "the child is unable to deal with that type of situation" or "his situation is that of the worker, constantly disturbing and confusing. ..."

What is most important is not to confuse this sense with two standard and frequent uses of the word situation: the [mere] location sense, which is synonymous with "place" and "position" . . . and "the external circumstances" sense which makes situations refer merely to an unrelated group of entities, a "set of facts" or state of affairs. (Mallin, 1979, p. 7)

It is fundamental to observe that "situation is not just one kind of "thing" among others, but is the ground ${ }^{2}$ or source of every form of existence" (Mallin, 1979, p.17; my italics). A situation is always a life-situation. Each of us is at any time necessarily "living a situation." What ever is the case, can be experienced, lived, only within a specific situation.

\subsection{The Timefull Structure of Situations}

Situations are endowed with a sense of time, embedded in a notion of continuity which is constantly forged by the tautening agency of an "intentionality" against the ground of a "being-previous." Below it is shown how.

\subsubsection{Introducing the "Being-Previous" in the Situation: It Is Derived from the} "Limiting-Concept" of a Totally New Situation

This (now-and-here) living situation is being on the grounds of a "beingprevious. ${ }^{3}$ In other words, being-previous is the ground from which a situation is

\footnotetext{
2 The word "ground" is being used both in the sense of "base" or "foundation" and in the sense of "substratum" from which something is distinguished (e.g., the surface worked up in painting - figureground).

3 "Being-previous" means "what is being previous" (observe the gerund).
} 
"situated." A totally new situation would be one that would not be situated on the grounds of the being-previous (everything would be new). A totally new situation would be a totally extra-neous (strange) situation. A totally extra-neous situation would be that in which nothing has been here before (being-previous). ${ }^{5}$ A totally extraneous situation would be totally unrecognizable, and hence it could not be being. Hence being-previous is the essential ground or principle ${ }^{6}$ from which presence is disclosed.

\subsubsection{Introducing "Intentionality": It Appears as the Noetic Acting Component of} Change, Which, in Turn, Is Derived from the Limiting-Concept of Absolute "Sameness"

In the above paragraph, it was stated: "a totally extraneous situation could not be being." The idea of a totally extraneous situation as a "limiting-concept" (in the mathematical sense) was used to bring forth the being of being-previous within the situation. The opposite extreme, "limit-concept," is now discussed. Could it be being a situation in which nothing is new, that is, a situation which is totally the same? To be totally the same means that there is no change; everything just remains as it was, everything is just frozen. If it were totally the same, it could not flow, it could not be-being. To be sure, if it were totally the same, it could not be the same, for there would not be a ground from which what remains could be distinguished from that which does not remain. A situation cannot, therefore, be frozen within the "sameness" of its pure being-previous. ${ }^{7}$ There must always be change in the situation and also there must always be something that remains in the situation. Without change there would not be that which remains. Without something that remains there would not be change. Change is alteration: it is action propelled from the ground of the being-previous and toward the extraneous, the not-yet-being, the forth-coming. ${ }^{8}$

\footnotetext{
${ }^{4}$ To "situate" is the verb derived from "situation." Hence, it has a wider sense than its usual meaning of placing or locating.

${ }^{5}$ Later, when discussing the notion of "self," it is shown that this limiting-concept of a totally extraneous situation corresponds to an absolute "otherness."

${ }^{6}$ According to Heidegger, "'Principle' comes from principium, beginning. The concept corresponds to what the Greeks call arche, that on the basis of which something is determined to be what it is and how it is. Principle: the ground on which something stands, pervading it, guiding it in its whole structure and essence" (Heidegger, 1981, p. 30).

${ }^{7}$ Later, when discussing the notion of self, it is shown that this limiting concept of pure sameness, or pure being-previous, would phenomenally correspond to a pure "selfness."

${ }^{8}$ The characteristic "extraneous" simply means that it has not been present before and consequently that its has not been organized within the becoming of my situations. The degree of novelty (or strangeness) can vary from the near-repetition of a previous situation to the sudden encounter with a "very strange" situation (e.g., the sudden appearance in this room of a very strange creature). Although the new situation may very closely resemble a previous one, there will always be a minor change: one affected at least by the fact that this is "present" and the other is "previous." When we are dealing with an extremely novel situation, there will always be "something" previous to which I could refer the change. The appearance of the strange creature, for example, would occur here and this would mean that I could, within this being here, "recognize" that which is undergoing change. This "recognition" will allow me to act, to struggle, to dominate, to make the new situation familiar.
} 
The pure acting or dynamic aspect of change is "intentionality," a sort of "principle of action" that situates the situation. To situate the situation is nothing but disclosing presence, letting presence become. This "action" of disclosing or becoming presence is called presencing. Intentionality thus, presences presence.

"Intentionality" or the "principle of action" can be understood as a sort of "readiness" for action (for perceiving, knowing, changing, maintaining). ${ }^{9}$ Every situation is recognized, appreciated, felt, placed, controlled, communicated, acted upon, etc., on the basis of such a "readiness." (Notice the acting, dynamic connotation of the word "readiness"). ${ }^{10}$ Under this perspective, being-previous is that which is ready in readiness/intentionality. That which becomes present is that for which readiness/intentionality is ready.

\subsubsection{The Intentional Object: That Which Is to Become Present}

It was stated before that "being-previous is the essential ground or principle from which presence is disclosed." Now, presence is orchestrated around that which is to become present. This is the focal object of presence (which provides its unity to presence). Hence, being-previous is thrown, through intentionality, toward such a focal object. Let it thus be called "intentional object."

Since, on the one hand, we are always living a present ("now-and-here") situation, and on the other hand, such presence is founded on the essential recursiveness between a being-previous (has been there before) and a being-thrown toward the forthcoming; therefore a notion of "continuity" pervades the situation. Continuity is what strings the sense of that "continuous succession" of situations that we call "time." Time is thus the essential recursive unity that springs from changing and remaining. Since intentionality always presences presence it provides its unity to continuity and, hence, to time.

\subsubsection{The "Self"}

This unity of continuity is phenomenally manifested by the "self." The "self" is thus a highly abstract notion indicating that which has been continually "here" in all "my" experiences, but which only is in so far as it is being-thrown through

\footnotetext{
${ }^{9}$ The term "readiness" is used by Sir Geoffrey Vickers in the following way: "I postulate that experience, especially the experience of human communication, develops in each of us readinesses to notice particular aspects of our situation, to discriminate them in particular ways and to measure them against particular standards of comparison, which have been built up in similar ways. These readinesses in turn help to organize our further experience, which, as it develops, becomes less susceptible to radical change. ... Since there are no facts, apart from some screen of 'values' which discriminates, selects and relates them, just as there are no values except in relation to some configuration of fact, I use the word appreciation to describe the joint activity which we call knowing and which we sometimes suppose, I think mistakenly, to be a separable, cognitive activity which is 'value-free"' (Vickers, 1970, p. 102).

${ }_{10}$ Observe that "intentionality," "principle of action," and "readiness" are different names for the same concept. We are using various names because each one discloses an important aspect of our notion of "intentionality." When we are interested in highlighting only one of these aspects, we use only one name; when two or more aspects are to be highlighted simultaneously, we write the two or more names together, separated by slashes, e.g., intentionality/readiness.
} 
intentionality. Below, this concept is examined in more detail. Before the question "What am I?" one possible answer is, "I am the subject/author of my doubting, my understanding, my acting, my being-there" ("I am the one who is thinking, writing, running, eating, etc."). In other words, confronting the question "What am I?" the first reply is an indication referring to the subject of my being-there (e.g., "I am the one" who is writing). But when one asks again, "What is this who?" no straight answer comes to mind. This second question about the whatness of the who tries to find an "actuality"11 (the who). When one scrutinizes the content of such actuality by questioning the identity of such "who" (What is that which is being indicated?), one does not find any content or actuality but rather the principle of action that manifests intentionality. However, this answer is not satisfactory, for although one recognizes oneself in such a volatile pure principle of action, one also intuits a more permanent and solid mode of the self which is, somehow, producing action. When before this unsatisfactory answer, one pushes again the question trying to find the content of the "itself" that in each case is my self, such a content seems to leap out of the question and seep into the "there" of my being-there (my writing, my inquiring, my feeling pain, etc.). Nevertheless, if the question about the who of my being-there is not forced to reach an actuality, the uncompromised question brings forth two modes of self.

The intention of answering the question, "What am I?" points simultaneously to intentionality and to something else from which intentionality springs. Intentionality is thus a sort of active mode of self: I am the principle of action in my writing, my running, my thinking, etc. This is the feeling of the acting principle that situates the situation. The feeling of my self cannot, however, be merely reduced to such an active mode of self. There is also a sort of "passive mode of self" which points to the unity of the being-previous. I am that which is writing, running, thinking, etc. This that is not an actuality or content; it is not a fixed, Eleatic being. It is a passive notion of continuity and identity which enables the reference of any situation to be made of a single becoming, "my" becoming. The "self" is within this mode, a highly abstract notion which indicates that which is constantly present in all "my" experiences. Whatever is left by all my experiences is strung together with the notion of "self." Hence, the self in its passive mode, is the synthetical phenomenal unity of the being-previous in the situation.

The former is not, however, an answer satisfactory enough before the question, "What am I?" The path of reflective thinking that has been followed led us to those two modes of self. Nevertheless, our self-intuition is not primarily split in

\footnotetext{
${ }^{11}$ Ancient Greek thought — particularly Aristotle's - distinguished two contrasting terms: "Potentiality" (Greek: "Dynamism") and "Actuality" (Greek: "Energeia"). Actuality is the static condition —in the Eleatic ontological sense - of being a concrete/determinate "form" or "content." "Potentiality" is the pure possibility of becoming (see Aristotle, 1928). It is the mere capacity/disposition to take form or content. (In Eleatic ontology, this is equal to the capacity/disposition to be.) These two concepts whose connectivity within the realm of Being remained obscure, made evident the failure of Eleatic ontology to explain change within its static conception of "beings." The condition of being has been taken to be that of "actuality" (in most of Western thought) (see Fuenmayor, 1991b).
} 
two modes. I primarily intuit my self as a fundamental unity, not as two different modes which appear only after thoughtful self-reflection has taken place. The present problem is thus to account on how these two modes of self merge into a phenomenal notional unity that transcends them. This can be done by uncovering the timeful essence of the situation. For this purpose, it is necessary to go back to our initial investigation regarding the limiting-concepts from which the phenomenological notions of being-previous and intentionality emerged.

The situation is not a structure which "moves along time." Time is not outside the situation. Time is not separable from the situation. Time is essential to the situation. Such a timeful essence is easily brought forth when we notice that by subtracting time from the situation the whole situation disappears. This was what was done above when the limiting-concepts of a totally new situation and a totally the same situation were presented. In the following these limiting-concepts are observed in the light of the notion of self.

\subsection{Revisiting the Structure of the Situation from the Perspective of the Self}

A totally new situation would be one in which being-previous would be totally absent. This means that the passive notion of self would be totally absent. However, as we argued before, such a totally new situation could not be-being, the principle of action could not be acting (it would be totally groundless due to the total absence of being-previous). Hence in a totally new situation there would not be the active notion of self. There would not be a self at all. A totally new situation would thus be pure "otherness." But, of course, this pure otherness could not be because such a situation could not be. Hence otherness cannot be pure; it only isbeing when being disclosed, as intentional object, on the grounds of a beingprevious (of a passive mode of self) that is activated through intentionality. Otherness can thus only be-being on the grounds of the self. However, as we shall see later, this limiting-concept of pure otherness acts as a sort of horizon from which the illusion of realism stems. The other extreme, a totally the same situation, is explained below.

A totally the same situation would be frozen within the sameness of its pure being-previous. This means that it would be a sort of solid, static, pure passive mode of self. Here, in this limiting-concept, it is finally found that content or actuality of the self which, otherwise, could not be found. But when it is apparently discovered, it is so dense that it is nothing. As was already argued, this frozen and absolutely dense sameness could not be-being. Therefore, as already concluded, being-previous, and hence, the passive notion of self can only be if it is being thrown toward otherness through intentionality. But this means that, on the one hand, the self can only be within the transcendental unity of its two modes, and on the other hand, this unity of the self can only be if it is being thrown to otherness in search of an intentional object. Solipsism is, thus, meaningless.

We cannot thus subtract time from a situation, for it would stop being. A timeless situation would not be at all. This means that the situation can only be if it 
is-being. Hence, the situation is-not; the situation is-being. The same can be said with regard to the notional unity of the self and with regard to the intentional object. I am not; I am-being (thrown to otherness). The intentional object is not; it is-being (disclosed on the grounds of otherness).

The timeful character of a situation is showing nothing but the recursiveness and the essential dynamics of an essential recursive form: \{Passive mode of self (being-previous) $\leftrightarrow$ otherness (forthcoming)\} are the recursive sides of a unitary, synthetic, "essential recursive phenomenon" called "intentionality." ${ }^{12}$ As such it is essentially dynamic. See Fig. 1.

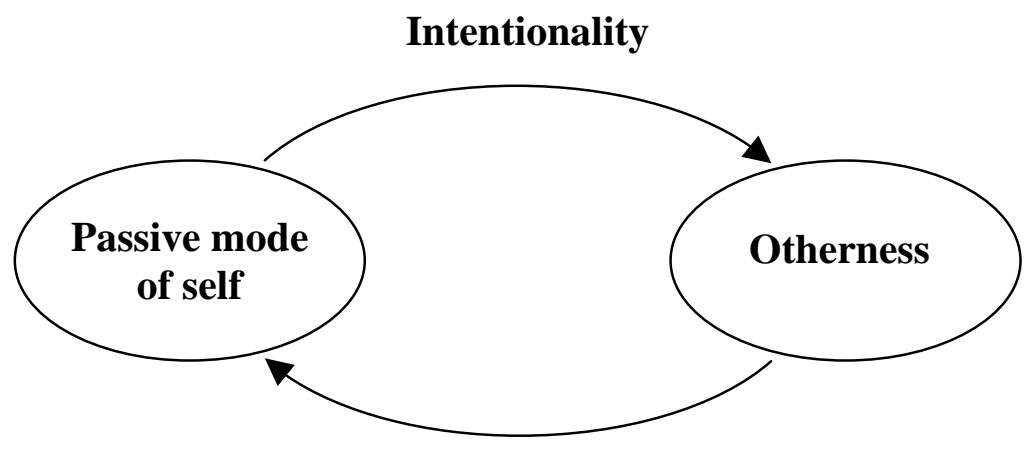

Fig. 1. The noetic side of the situation.

The investigation carried out with regard to the concept of "situation" and its constitutives brings about a sort of contradiction with respect to the initial statement which started the inquiry. At the beginning it was written: "what-ever-is-the-case is only possible within a present (now-and-here), particular, concrete, circumstantial situation." Now, the essential recursive unity described above is showing that the instantaneous character of the situation, defined in that initial statement and represented mainly by intentionality, is possible only on the essential recursive ground of the noninstantaneousness of passive mode of self and otherness (forthcoming). The situation thus provides the ground for its instantaneousness and its temporal transcendence toward and from the non-instantaneousness.

The above description in terms of essential recursiveness has also accounted for the unity of the two basic modes of self. However, as shown later, this is only a partial account of this unity.

The former revisiting of the initial limiting-concepts reveals, on the one hand, the timeful essence of the situation and, on the other, that the logically independent notions of self and otherness, which characterize dualism (and which give rise to both realism and solipsism), are mere illusions arising from the threat that the phantoms of those limiting-concepts impose on the situation. Let this last

\footnotetext{
${ }^{12}$ When the form of essential recursiveness was described (Fuenmayor, 1991a), it was explained how the essential recursive sides (hands) have a sort of elusive/intermittent/fleeting presence. Each one seems to be there as a static mirage; but when one tries to focus this and to trap it into an actuality, it "moves away", merging into the unity of the essential recursive form.
} 
point be clarified.

It was demonstrated that the limiting-concepts of a totally new situation (which purports the notion of pure otherness) and of a totally the same situation (which purports the notions of pure being-previous and pure passive mode of self) cannot be-being. This means that the dualist notions of independent otherness and independent (passive mode of) self are inconceivable in the "reality" of now-andhere situations. "Reality" is nothing but the be-being character of a situation. Pure otherness and pure passive mode of self belong to a sort of "horizon" always beyond reality - beyond the be-being of the situation - but which continually threatens such reality. Therefore, it is a horizon which somehow is always there in the shadow of the situation. Pure otherness and pure passive mode of self (pure being-previous) are thus a sort of "horizonal" notions which threat the living or bebeing character of the situation and its constitutives. But how could this be-being be if not distinguished from a not-be-being? Paradoxically, these static horizonal notions constitute the horizon, or rather the ground, from which the be-being character of the living situation and its constitutives emerge. Hence, these horizonal notions both threaten reality and provide the ground for reality. This means that the horizonal notions are not being as the other constitutives of the situation are being in the situation. While the latter are-being, the former are-not-being; they just are forms of "nothingness" from which "somethingness" stems. ${ }^{13}$ In this way both horizonal notions merge in one. They become, in their "limits," that nihilizing background that both opposes and makes possible the be-being character of intentionality. In other words, horizonal notions of pure otherness and pure beingprevious (pure passive mode of self) represent a sort of negative power against intentionality in its continuous disclosing of presence. Let me briefly stop at this point for it shows the ontological root of power and will.

\subsection{Intentionality, Power, and Will}

"Situating" or "presencing" means to be-being thrown from the ground of the passive mode of self towards otherness. Otherness is both the extraneous (not yet "intraneous," not yet intimate) and the forthcoming (not yet previous). Intentionality is the positive power that lets beings be-being. This positive power can only be if it is reacting against the negative power conjured in and launched from the "limits" of pure sameness and total alteration.

As shown, pure sameness and total alteration correspond to the horizonal notions of pure being-previous (pure passive mode of self) and pure otherness.

Pure being-previous, understood as a threat against intentionality, represents, in the situation, the influence, and hence, the power, of culture and history against

\footnotetext{
${ }^{13}$ Their estrange form of be not-being also provides an explanation of the origin of dualism. Dualism has, along the history of Western thought, arisen from the confusion about the ontological status of these "not-bebeings" having been confused with "be-beings." The horizonal notions are thus a sort of mirage or illusion which delude thinking. The result of such a delusion is dualism in any of its two forms of realism or solipsism.
} 
the situational individual in his strife for autonomy. This was Kant's concern, commented on in a previous paper in this special issue (Fuenmayor and LópezGaray, 1991). Freedom, in the Kantian sense, is what is striven for in the reaction against the power force that being-previous imposes on intentionality. Such reaction can be channeled through critical thinking, which strives for autonomy. Critical thinking seeks to unconceal the ways in which being-previous (a priori conditions in Kantian jargon) prevails upon presencing. ${ }^{14}$ Since being-previous is the ground from which presence is disclosed, it gives both its possibility and its impossibility to freedom.

On the other hand, pure otherness, understood as a threat against intentionality, represents the alien, the "outside" forces which oppress intentionality in its thrust. ${ }^{15}$ These are the so-called (within realism) "oppressing material conditions."

As already argued, without being-previous and/or without otherness intentionality could not be-being. However, the horizonal notions of pure beingprevious and pure otherness which ground the be-being character of being-previous and otherness represent the negative power against intentionality. This means that both being-previous and otherness make possible and restrict intentionality. In turn, as already stated, intentionality is the positive power against that negative power. Both the source of such positive power and what is gained in its strife is freedom. ${ }^{16}$ This essential recursive unity of positive and negative power is power in its ontological root. Here, we also find the ontological root of will.

Will, in its ontological root, is manifested intentionality along a particular intentional object in its strife for positive power with regard to such an intentional object. Intentionality can be seen as the continuous struggle against otherness in order to make it familiar, i.e. for otherness to become being-previous. Such strife is, in each particular situation, conducted along the disclosure of an intentional object from the background of otherness. When such a disclosure around a particular intentional object persists, so that the persistence manifests intentionality as the sustained strife for the intentional object, we speak of will. Manifested intentionality is always will. And will is always will to power. ${ }^{17}$ Heidegger, in his interpretation of

\footnotetext{
${ }^{14}$ This subject of unconcealing being-previous is treated by Fuenmayor (1991b) in relation to truth.

${ }^{15}$ According to Mallin, "We can broaden our understanding of situations by considering the personal development of the child. ... From his birth, he is perpetually confronted with the foreign, alien, contingent, and unpredictable. As Hegel has shown, his maturation is the overcoming of this otherness by appropriating it and making it non-other to himself. Hence, the child will expend much energy in acquiring patterns of behavior that will organize his cultural surroundings, giving him a measure of control over them. He will painfully learn how to act in standard social contexts, and his dealings with others will be arranged in terms of a perpetually evolving schema. He will also be occupied with situations of a personal nature which attempt to comprehend the bearing that inability, loneliness, anxiety, and independence have on his life" (Mallin, 1979, p. 11).

${ }^{16}$ Observe that this is a more embracing and deeper notion of "freedom" than the Kantian one presented before.

${ }^{17}$ This is the ontological foundation from which a theory of will and power for Interpretive Systemology is to be developed.
} 
Nietzsche's "Will to Power" describes will with these words:

... If will is willing out beyond itself, the "out beyond" does not imply that will simply wanders away from itself; rather, will gathers itself together in willing. That the one who wills, wills himself into his will, means that such willing itself, and in unity with it he who wills and what is willed, become manifest in the willing. In the essence of will, in resolute openness, will discloses itself to itself, not merely by means of some further act appended to it, some sort of observation of the willing process and reflection on it; on the contrary, it is will itself that has the character of opening up and keeping open. No self-observation or self-analysis which we might undertake, no matter how penetrating, brings to light our self, and how it is with our self. In contrast, in willing and, correspondingly, in not willing, we bring ourselves to light; it is a light kindled only by willing. Willing always bring the self to itself; it thereby finds itself out beyond itself. It maintains itself within the thrust away from one thing toward something else. (Heidegger, 1981, pp. 51-52)

The persistence that characterizes will provides the possibility for the persistence and identification of the self and of what ever might be the case. ${ }^{18}$

\subsection{The "Self" and "the Others"}

How the unity of the self transcends its two basic modes has been accounted for. Nevertheless, this has only been a sort of "internal" account of such a unity. It really does not reveal the distinctive character that is necessary for a unity to be such. This distinctive character is usually called "identity." In order to reveal the identity of the transcendental unity of the self, it must be distinguished from what it is not. In other words, although we have discovered that "I am that which has been continually here in all my experiences, and which only is insofar as it is beingthrown to what becomes present through intentionality"; we do not yet know what is the source of my identity. The question we have now in front of us can be put in different forms: "What am I being distinguished from?" and "How am I possible as a distinctive unity?"

The last wording of the question gives a clue. "How am I possible as a distinctive unit?" can also be phrased as "How am I possible as a distinctive one?" But here we find that "one" is one of the words that refers to the self. "One" is the anonymous self. "I am one of the persons who were. . ." reveals my self as a unity among other unities - the others - of the same species. I am "one" (I am a unity) because there are "others" like me. Observe that this unity of the self refers mainly to the passive mode of self, for "to be one among the others" refers to such a passive notion. The identity of the self is, thus, pointing to the unity of the passive mode of self.

I would not feel an "identity," a "self" ("I myself"), if "the others" would not be there. "I myself" is possible because there are others who are like "I myself." There are others who can see me and see that which is not me, as I see each one of

\footnotetext{
${ }^{18}$ This subject of persistence and identification is treated in more detail further on.
} 
them and see that which is not them. "I myself" is nothing but my claim to be one among "the others." That is to say, I am "one-other" (another). "One-other" is any possible other: "the other." Hence, "the other" is constitutive of myself. Just to the extent that I distinguish myself from "the other" (so that I identify myself), I am "the other" and "the other" is me. But at the same time "I myself" is a claim to be a different unity from "the others." "I myself" is the distinction from "the other." Without the presence of "the other," "I myself" could not be. ${ }^{19}$

On the other hand, "the other" is "other like me." "The other" is "other-one"; that which in each case is I myself. This means that the notion of "the other" is not possible without the notion of "I myself."

"I myself" and "the other" are then recursive sides of an essential recursive form.

Since the identification of the unity of the passive notion of self cannot be without "the other," and "otherness" cannot be without the unity of the passive notion of self, "otherness" cannot be without "the other." Thus, "the other" is also the ground for the separation or "distance" between the passive mode of self and otherness. If there were not "the other," there would not be either otherness or identification of the self. This means that "the other" not only provides the ground for the separation between otherness and the identification of the self, but also provides the ground for their mediation. As shown in Section 3, this ground for separation and mediation is also the ground for the identification of that which becomes present, of that which is distinguished as such.

The investigation carried out so far has brought forward an answer to the old question: "What am I?" I am the unitary notion/label/feeling of being-previous, manifested as a unity through the essential recursive phenomenon \{"I myself" $\leftrightarrow$ "the others"\}, and which is continually being thrown into what is present through intentionality. ${ }^{20}$

\subsection{The Place of the Notion of "Self" in the Phenomenological Ontology}

Observe that the ontology being outlined does not start, as Descartes does, from the aprioristic reduction to an "I" (res cogitans) who is thinking (doubting) (see Fuenmayor, 1991a). It starts from any "this situation." "Situation" is the primordial phenomenological concept which contains/represents the totality of existence in any "now and here." This means that the givenness of the situation implies the givenness of the notion of "self," of the notion of being-previous and of whatever belongs to that intimate/familiar side that can be called "subject-side." However, as opposed to Descartes, the givenness of the situation (within this

\footnotetext{
${ }^{19}$ Heidegger presents the action of moral conscience (the call of conscience) as the most clear possibility for encountering an authentic "I myself." The call of conscience can be taken as a trial that takes place in the individual conscience when the notion of "the other" is summoned in order to be the jury at such a trial (Heidegger, 1962). This, we think, constitutes a basis from which a theory of practical reason can be developed on the grounds of the ontology of interpretive systemology.

${ }^{20}$ The theme of "the others" constitutes the ontological foundation for a social theory for Interpretive Systemology founded in its ontology.
} 
phenomenological approach) also implies the givenness of otherness, of "the other," of some intentional object and of whatever belongs to the "object-side." The ontology being outlined does not start from the reduction to an aprioristic "I" (which is nothing but the subject of my doubt), but from a notion of "self" essentially, originally, and irremediably compromised with the situation. ${ }^{21}$ This being the case, the phenomenological ontological task consists of describing how all phenomenal notions ("being-previous," "present," "self," "otherness," "the other," "intentional object") merge into the situation.

\subsection{The Sides of the Situation}

So far the concept of situation has been described in terms of intentionality. Intentionality has been presented as the essential recursive phenomenon whose essential recursive sides are being-previous and otherness. Intentionality is the fundamental possibility for the disclosure of any situation (for the situating of any situation). It was further stated that the "situation" is the ground for any form of existence - it is the ground for whatever is "taking place." Intentionality is then the fundamental possibility for whatever is "taking place" (it is the fundamental possibility of whatever could be the case). But does intentionality really account for "that" which is "taking place " - the intentional object? The former description of intentionality has concentrated on being-previous and has paid little descriptive attention to the other recursive side: otherness. This indicates that the description has been, so far, subject-side biassed or, in Husserlian terms, has been a noetic description.

Intentionality could not be explained without considering otherness. In other words, the former ontological description of a situation in which intentionality takes center stage is incomplete unless otherness is treated in greater depth. ${ }^{22}$ It is important to notice that the former statement does not mean that only one "element" of some structure has been considered and that the other "element" will be considered next. This is in no way the case. The whole situation has been seen from one point of view, a noetic (subject-side) point of view. Now the whole situation must be seen from the other side, namely, from a noematic (object-side) point of view.

\section{THE NOEMATIC SIDE OF THE SITUATION: DISTINCTION}

How is the intentional object phenomenally present in the situation? What does, phenomenologically speaking, "to take place" (to occur) mean?

Intentionality is intending an intentional object. It was stated before that intentionality could be seen as the continuous struggle against otherness in order to make it familiar, i.e., for otherness to become being-previous (the passive mode of

\footnotetext{
${ }^{21}$ Heidegger uses the term "being-in-the-world" to designate the unity that the self forms with the world (Heidegger, 1962, pp. 78-90).

${ }^{22}$ It would appear that most of the work developed under the trend of Phenomenology has a rather subjectside bias.
} 
self). This "appropriation" of otherness into being-previous is mediated by "the other." Such strife (will to power) is, in each particular situation, conducted along the disclosure of an intentional object from the background of otherness. This strife for disclosing an intentional object is a distinguishing from the background of otherness. Distinguishing is presencing. Distinguishing draws up a distinction. A distinction is what is presented. The "appropriation" is attempted through the identification of the distinction. The former compact announcing of the noematic side will be seen in more detail as follows.

The action of intentionality brings about a distinction. The noetic intentional object is to become a distinction on the noematic side. This implies that, from the noetic point of view, the distinction is a sort of severance that the action of intentionality performs on that noematic ground that can be called "otherness." ${ }^{23}$ Notice that while the intentional object is-being, the distinction has-been. Put in other terms, while the "time" of intentionality is the gerund, the "time" of the distinction is the present perfect. So the "has-taken-place" is a distinction. What has been distinguished has been distinguished from its scene. A tree has been distinguished from its scene; a feeling of hunger has been distinguished from its scene; the making of a table has been distinguished from its scene; an image of the face of somebody who is not here has been distinguished from its scene; a feeling of uncertainty has been distinguished from its scene (notice that distinctions are not merely "material things"). A distinction is thus a "has-been-being" or a presence, whereas an intentional object is a "be-being," a "not-yet-has-been-being." An intentional object is a not yet presence which is not past but "be-being."

Nevertheless, the tree, the feeling of hunger, etc., are not necessarily distinguished as such. That is, they are not necessarily identified as such. I turn my head and see a door. This means that what has been distinguished has been identified as a door. It is a door. The mere "it" is a distinction. I would not be able to talk (to indicate through language to others) about my distinction if I do not identify it as such. So while the "it" is the distinction, the as such is its identification. Through identification, the accidental and fugacious character of the distinction is grabbed into "something" which is both perdurable and speakable. Through identification a distinction is "rescued" from otherness. Through identification the "it" becomes the same with itself. Through becoming the same with itself, it gains its "itself" - it gains its identity. But this becoming the same with itself so that it is

\footnotetext{
${ }^{23}$ The following quotation taken from Spencer-Brown's "Laws of Form" metaphorically helps to illustrate this notion of "distinction": ". . . A universe comes into being when a space is severed or taken apart. The skin of a living organism cuts off an outside from an inside. So does the circumference of a circle in a plane. By tracing the way we represent such a severance, we can begin to reconstruct, with an accuracy and coverage that appear almost uncanny, the basic forms underlying linguistic, mathematical, physical, and biological science, and can begin to see how the familiar laws of our own experience follow inexorably from the original act of severance. The act is itself already remembered, even if unconsciously, as our first attempt to distinguish different things in a world where, in the first place, the boundaries can be drawn anywhere we please. At this stage the universe cannot be distinguished from how we act upon it, and the world may seem like shifting sand beneath our feet" (Spencer Brown, 1969, p. v).
} 
speakable and perdurable is, with the same priority, a becoming "the same" for me and for "the other." To be the same with itself and to be the same for me and for "the other" are the same. What this last sentence means is that "sameness" is an essential recursive form whose sides are "the same with itself" and "the same for me and for the other." The same with itself could not be without the same with the other, and vice versa. In turn, sameness could not be without the synthesis of both sides. This essential recursion becomes clearer if we remember (from Section 2.4) that "the other" is the ground for mediation between my self and otherness. Hence, as stated at the beginning of this section, the "appropriation" of otherness into being-previous is performed through the identification of what becomes present. Notice that once an identification is obtained, a qualification or determination may be made over such an identification.

In the counter-ontoepistemology for a systems approach (Fuenmayor, 1991a) it was shown how the principle of noncontradiction announces an ontoepistemology which has guided Western thought to the path of Reductionist Modern Science and its mathematical project. Indeed, the principle of noncontradiction is the negative version of the principle of identity. To be the same with itself ("A is A") is what is announced by the principle of identity. But we have already shown that something is the same with itself if and only if it is the same for me and for "the other." Now it can be seen with more clarity what Parmenides implied by saying, "[The only path offered to thought is] that which affirms that being is and non-being is not. This is the way of persuasion since it accompanies truth" (Parmenides, 1975, p. 49; See Fuenmayor, 1991a, pp. 427-430). Only if what becomes present is the same with itself can it be the same for me and for the other; this is the way of persuasion. This dual sameness, Parmenides tells us, constitutes the principle of truth. Thus, the principle of identity (or noncontradiction) has been the principle of principles throughout Western thought. But how does sameness, in its essential recursive form, constitute the principle of truth? This question is treated in the paper devoted to the epistemology of interpretive systemology in this issue. Here, on the ontological side, a crucial point still has to be clarified.

The previous discussion about "identification" could lead to thinking that the identification of what is identified is equal to that which is identified. That which is identified is a distinction. The identification is the product of identifying the distinction. The distinction is what has been presented. Hence the identification should not be confused with that which has been presented. To be sure, such a confusion between the identification and the presented is the source of reductionism in Modern Science. The identification is indeed a face or side of the presented, but the presented cannot be reduced to the identification. Let us see why.

\subsection{Distinction: An Essential Recursive Form Whose Sides Are "distinction" and "Scene" \\ When the notion of distinction was introduced, before the discussion about identifying, it was stated that the "distinction is distinguished from its scene." What}


are, in terms of the situation, the distinction and the scene? A first attempt to answer: the distinction is that which has been distinguished from the scene. The scene is that from which the distinction has been distinguished. Such answer shows that the "whatness" of the distinction is referred to -or, more properly, transcends to- the scene and that the whatness of the scene moves to the distinction. Scene and distinction (with lowercase "d") are, logically speaking, the recursive sides of an essential recursive form called Distinction (with capital "D"). See Fig. 2.

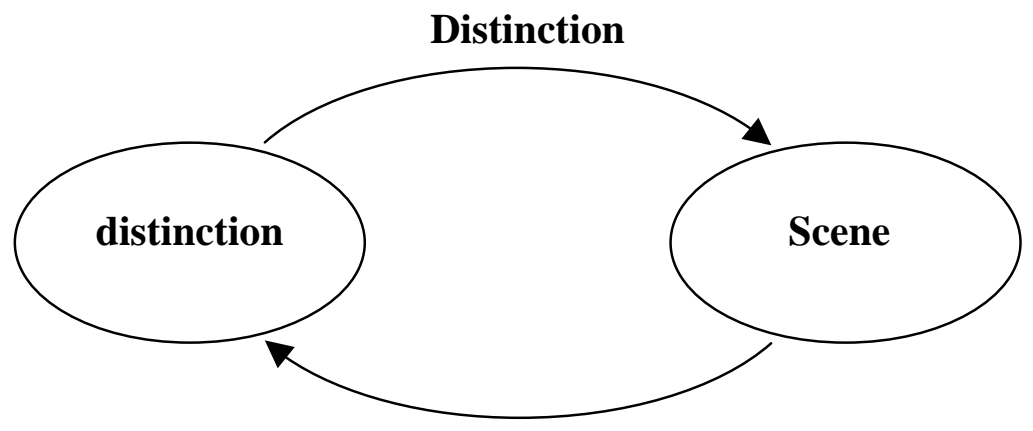

Fig. 2. The noematic side of the situation.

Now what else is there to know about the whatness of each one of those essential recursive sides of the Distinction?

\subsection{The "Indicability" of the distinction and the "Unindicability" of the Scene}

The questions about each one of the sides of the Distinction slip out and merge into the whole of the essential recursive form. Nevertheless, there is an important difference between both sides: the distinction can be indicated (intuitively determined). This is why it can be identified and, hence, objectified. The scene, on the contrary, is essentially "unindicatable." It remains completely elusive. To explain further: I see/touch (have seen/have touched) this thing in my hand. "This thing" means an indication to some other person of a distinction. The demonstrative adjective "this" thus implies a pointing out. Now, this "pointing out" or indication is transcended in its accidental and particular status through its identifying. The indication thus also becomes an identification. Recall that the identification is the result of the attempt to make the distinction the same with itself and the same for me and for the other.

When we want to transcend the mere indicative identification by asking "What is this (pencil)?" we are faced with the attempt of thetically ${ }^{24}$ determining the distinction. Such thetical determination requires finding out what makes it different

\footnotetext{
${ }^{24}$ The term "thetical" or "thetic" refers to thesis and stems from the Greek word thetikos, from thetos, meaning laid down, from tithenai, meaning to place. Here, the word thetical is used to refer to that which is thought about $\mathrm{X}$ when trying to answer the question "What is $\mathrm{X}$ ?" This is being differentiated from the simple indication of $\mathrm{X}$.
} 
from anything else. ${ }^{25}$ This is nothing more than an essential reference to the scene of the distinction. The distinction can then be indicated but its thetical determination "slips out" into the scene. This "slipping out" is a Holistic Transcendence from the distinction to the scene.

The indicability and identifiability of the distinction, together with the horizonal notion of pure otherness, create an "illusion" of determination in-itself. However, reflection reveals that the thetical determination of the thing (Distinction) is essentially transcendental. This transcendentality springs from the form of essential recursiveness in which the Distinction is rooted. Observe that the ontological position being described provides a framework where the pivotal idea of a Systems Approach - the phenomenon of Holistic Transcendence - is meaningful. This point is treated in more length at the end of this ontological outline.

A first examination of the distinction (as a side of the Distinction) has revealed its indicability, its identifiability, and its essential transcendence into the scene. Can the same be said about the other recursive side: the scene? From what is the pencil being distinguished? Is it from my hand? Why not from the desk? Why not from this room? Why not from other colors or shapes? There can always be something else from which to distinguish the pencil. One might think that the distinction is being distinguished from each possible object, genus, or property. This is not the case, as shown below.

As already explained, the distinction is previous in each case to any description, analysis, or reflection which may enrich this original distinction. It is a sudden discovery which does not allow a one-by-one comparison with other objects. If the Distinction would require an individual (one-by-one) distinguishing from any other possible thing, or from those in proximity to the distinction, the instantaneousness of its indication would not take place. Hence, there would not be a Distinction. Besides, this idea of the "Distinction," as the distinguishing from a set of other things, presents a fundamental logical impossibility: if the distinction of the pencil implies the distinction from my hand, from the desk, from the room, etc., my hand, the desk, the room would be now distinctions from new scenes. That is, such explicit comparison would imply new distinctions. In this way, the original scene would "disappear" due to its fragmentation into new distinctions. Therefore, the original distinction would not have occurred.

The question about the whatness of the scene remains essentially elusive if one tries to find its constitution. The elusive being of the scene cannot be disguised

\footnotetext{
${ }^{25}$ Logically speaking, a definition is composed of a genus proximum and a differentia specifica. Genus proximum is the nearest set to which the object being described belongs. Differentia specifica are the attributes of the object which make it different from any other of the genus proximum. For example, "piano" is defined as a "musical instrument [genus proximum] in which stretched metal strings are struck by hammers operated by keys" [differentia specifica] (Oxford Advanced Learner's Dictionary of Current English, 3rd ed., 1974; my brackets). Both genus proximum and differentia specifica are indications of that which the object being defined is not. Genus Proximum implies a disregarding of any other genus or set. Differentia specifica shows the differences between other objects of the Genus Proximum.
} 
under an identification (it cannot be disguised as an "object" or a "set of objects"). The scene is the essentially dynamic ground from which "each " distinction is liberated. It is the possibility of what is being actualized. It is the "impletion" of intentionality into a particular disclosure which discloses the distinction. Such a process cannot be but elusive.

\subsection{The Elusiveness of the Scene Makes Impossible the Thetical Determination of the distinction}

This paper has been dedicated to the ontology of situations. However, since such ontological research is performed in order to sketch an epistemology for the Systems Approach, it is convenient to surface a major epistemological problem which has been generated by the elusiveness of the scene.

It was previously established that the thetical determination of a distinction has to explore the scene which makes possible such distinction. However, each particular scene is thetically elusive. Then, how could the search for true knowledge - the intention of thematic determination - be performed? What are the possibilities of the scientific enterprise in reference to the former ontological ideas? These questions define the primary task of designing an epistemology (Fuenmayor, 1991b) coherent with the ontology outlined. Now, the ontological discussion is ready to perform a noematic incursion into otherness.

\subsection{Otherness and Being-Previous: The "Scenario" of Any Scene}

As discussed in the description of the noetic side of a situation, there is in the situation a notion of continuity (of identity) noetically represented by beingprevious. In turn, being-previous is manifested through the passive notion of self, which, through the identifying of the self, is the synthetical unity of being-previous. The following shows that this "continuity" also has its noematic face.

While the passive mode of self is a phenomenal notion that accounts for continuity on the noetic side, the continuity of otherness through situations is the phenomenal notion that accounts for continuity on the noematic side. The continuity of otherness through situations (on the noematic side) is the "scenario" of any scene. It is the ever-present background from which "any" (observe the difference between "any" and "each") distinction comes forth. Notice the difference between "scenario" and scene: the scene is the instantaneous/particular ground that opens the possibility of each instantaneous/particular distinction, whereas "scenario" is the continuous/general ground that opens the possibility of any distinction. Within our phenomenological purview, the world is the scenario of any scene. Such a notion of the world is obviously quite different from that of reductionist science. According to the latter, the world is the collection of things "out there."

Within the noetic purview, being-previous was characterized as the essential ground from which presence is disclosed. In turn, it was stated that presence is disclosed around the intentional object. The intentional object becomes a distinction on the noematic side. Therefore, from a noetic point of view, being-previous 
constitutes a continuous scenario which opens the possibility of any distinction. However, in the above paragraph the same proposition with regard to otherness instead of being-previous was stated. How, then, can both otherness and beingprevious merge to constitute such a scenario for any scene? The answer to this question was already given in the noetic description of the situation: horizonal notions of pure passive mode of self (hence, pure being-previous) and pure otherness merge into a horizon which both threatens and makes possible reality (the be-being character of the situation).

Here, from the noematic purview, we find again the merging together of being-previous (passive mode of self) and otherness (forthcoming) in their "limits." Continuity, the span of time, lays across both sides of the situation. From the noetic side perspective it shows itself as the passive notion of self, the synthetical unity of being-previous. From the other side, it is felt as the forthcoming, the temporary face of otherness. The passive notion of self and otherness (being-previous and the forthcoming) constitute, across both sides, the scenario which feeds each scene so that the possibility of a distinction is opened. This means that, although the scene is essentially elusive, it is being "fed" (or horizonally constituted) by being-previous and otherness in their merging together.

Intentionality, which noematically is seen as a distinguishing, provides the unity of the situation. Both sides become one through the merging together of being-previous and the forthcoming. The unity of the situation provides, in turn, the transcendental holistic character of the distinction.

We thus have come back, after the phenomenological examination of the situation, to its fundamental unity.

The former ideas constitute the sketch of an ontological position in which the phenomenon of Holistic Transcendence - the conceptual cornerstone of a Systems Approach - takes full meaning. In order to be more explicit the original problem, presented by Fuenmayor (1991a), is recalled.

\section{IN PLACE OF A CONCLUSION: FROM "EMERGENT PROPERTY" TO "PHENOMENON OF HOLISTIC TRANSCENDENCE"}

The fundamental ontological idea of the Systems Movement has been that of emergence ("emergent property"). "Emergent property" is a term that indicates the amazement and the uncertainty caused by the failure of Reductionist Science to explain the wholeness and transcendentality of the object of study. Nevertheless, it is also a term whose meaning is profoundly rooted in the very ontoepistemological substance of Reductionist Science. Let this be explained.

Reductionist Science conceives of the world as a collection of objects (independent things) connected to each other within a universal order. Objects are bodies (res extensa) presenting a common phenotypic property (extension) and a common genotypic (or metaphysical) property (atomic constitution). Bodies present a regular "behavior" given primarily in reference to an external space-time grid. Such regular and interconnected behavior of all bodies within the world, expressed 
in terms of accurate mathematical laws, is "nature." Now, just as the world is constituted by a set of interconnected objects, each possible object of study (which is a generic object, e.g., "body") is constituted by a set of interconnected parts whose connected behavior is the behavior of the whole object. In this order of ideas, it is completely proper for reductionist science to be concerned with designing models which describe the interconnected behavior of all the elements of the phenomenon to be studied. Those elements are mere identifications. The models depict relations among identifications. That is, when the Systems Movement claims the designing of "systemic models," conceived as representations accounting for the multiple interrelation of already existing (aprioristic) elements, it is not presenting any new paradigm whatsoever. Such a claim is, at most, a methodological improvement of the most essential intentions of Reductionist Science.

"Emergent Property" means those features which emerge from the interconnected behavior of already existing parts and which are not exhibited by any of the parts in isolation. It is a property that is assumed to be the result (the effect) of the multiple interaction of all the parts. Here, emphasis is given to the fact that such an idea of emergence is founded on a Reductionist Ontological position and on the difficulty, within Reductionist Science, of explaining a holistic behavior which does not belong to any of the parts.

Things are manifested as system-wholes. This is an intuition which cannot be denied by Reductionist Science. However, the idea "emergent property" is dogmatically based on the assumption that such wholeness is a result of the interacting of its parts. Hence, such an idea, which apparently is leading an ontoepistemological revolution, is trapped in the aprioristic Reductionist assumption that the world (and each object of study) is a priori constituted by an independent (from the observer) set of interconnected parts from which new properties emerge.

Under the light of the Systemic Phenomenological Ontology outlined above, "emergent properties" are neither "emergent" nor "properties." The notion of Holistic Transcendence, implied in the concept of emergent property, is explained by means of the concept of situation and its essential recursive sides: Distinction and Intentionality. In this way Holistic Transcendence finds an ontological answer which is to lay the ontological foundation of a Systems Approach conceived as a new ontoepistemological paradigm.

A thing is not a thing-in-itself. A thing is a holistic transcendental phenomenon whose transcendentality can be understood in terms of the essential recursive form Distinction. Since the unitary being of the thing is essentially rooted in its scene, it is obvious that the collection of parts cannot explain such unity.

At the outset of the preceding paper (Fuenmayor, 1991 a), it was stated that the ontological claim of the Systems Approach (condensed in proposition SOP) could not be separated from the epistemological concern of studying things as if they were transcendental wholes (proposition SEP). That is (in terms of the present systemic-phenomenological model), the epistemological concern is about the possibility, limits, and methods of studying things as Distinctions. This 
epistemological question is treated in the following paper (Fuenmayor, 1991b).

\section{ACKNOWLEDGMENTS}

Thanks are due to Dr. Abdel Fuenmayor and to my colleagues in the Interpretive Systemology Research Group, Jorge Dávila, Hernán López-Garay, and Alejandro Ochoa, for their helpful comments on and criticisms of the manuscript. I also want to express my gratitude to Michele Lee for her careful proofreading.

\section{REFERENCES}

Aristotle (1928). The Works of Aristotle, Oxford University Press, London.

Astorga, J. (1967). Génesis del naturalismo en el arte de Occidente (mimeographed), Facultad de Humanidades y Educación, Universidad de Los Andes, Mérida.

Fuenmayor, R. (1991a). The roots of reductionism: A counter-ontoepistemology for a systems approach. Syst. Pract. 4, 419-447.

Fuenmayor, R. (1991b). Truth and openness: An epistemology for interpretive systemology. Syst. Pract. 4, 473-490.

Fuenmayor, R., and López-Garay, H. (1991). The scene for interpretive systemology. Syst. Pract. 4, 401-418.

Heidegger, M. (1962). Being and Time, Basil Blackwell, Oxford.

Heidegger, M. (1981). Nietzsche. Vol. 1. The Will to Power as Art, Routledge \& Kegan Paul, London.

Mallin, S. (1979). Merleau-Ponty's Philosophy, Yale University Press, New Haven, Conn. Parmenides et al. (1975). Fragmentos, Ediciones Orbis, Barcelona.

Spencer Brown, G. (1969). Laws of Form, George Allen and Undwing, London.

Thevenaz, P. (1963). What is Phenomenology? Merlin Press, London.

Vickers, G. (1970). Freedom in a Rocking Boat, Penguin Books. London. 